\title{
A representação do cinema no Jornal Português: da capital das vedetas à agenda de António Lopes Ribeiro Ricardo Vieira Lisboa ${ }^{1}$
}

\section{Objeto de estudo}

O Jornal Português (1938 - 1951) - "a primeira revista cinematográfica produzida continuamente em Portugal" (Piçarra 2015, 8) constitui a primeira edição em DVD da Cinemateca Portuguesa Museu do Cinema em nome próprio ${ }^{2}$. O jornal apresenta-se na sua extensão completa apesar dos dois números perdidos, de outros dois sem banda de som, de alguns números com lacunas e da introdução de números especiais e outros cuja identificação não está certa (passando a coleção dos 95 números anteriormente reconhecidos para os presentes $101 \mathrm{e}$, portanto, acrescentando uma hora de material inédito) (Baptista e Machado 2015). Esta série de atualidades que foi exibida entre fevereiro de 1938 até meados de 1951 é composta por números com duração aproximada de 10 minutos que foram sendo distribuídos a intervalos irregulares (sendo a média 45 dias de intervalo entre cada número). A maioria destes números é composta por uma série de reportagens, havendo, no entanto, números especiais dedicados a um único tema. Assim, e de acordo com o Relatório sobre a edição do "Jornal Português" de 1951 por Francisco Correia de Mattos editado em versão fac-similada no livrete que acompanha a presente edição em DVD, estrearam-se 101 números num total de 510 "assuntos" dos quais 16 eram de notícias cedidas por noticiários estrangeiros (Mattos 1951, 30). Estas reportagens discorriam sobre temas vários (ainda que pouco diversificados) sendo o interesse principal do Jornal Português a política, a economia e os trabalhos militares $-48.5 \%^{3}$ - o que justifica a afirmação da historiadora Maria do Carmo Piçarra de que "a série não prima pela diversidade temática" (Piçarra 2015, 11).

É importante ter noção de que o subtítulo do Jornal Português, Revista Mensal de Actualidades, erra três vezes: primeiro, porque a

\footnotetext{
${ }^{1}$ Instituto Politécnico de Lisboa, Escola Superior de Teatro e Cinema, 2700-571 Amadora, Portugal.

${ }^{2}$ A 14 de Maio de 2015 já haviam sido editadas, em parceria com a distribuidora Midas Filmes, as duas primeiras obras de Paulo Rocha restauradas digitalmente, Verdes Anos (1963) e Mudar de Vida (1966).

${ }^{3}$ Mais uma vez segundo Piçarra, os Trabalhos Militares constituem 21\% do acervo, a Política Interna 10,5\%, a Política Externa 6\% e a Economia 11\% (Piçarra 2006, 159). Note-se, no entanto, que estas percentagens foram feitas pela historiadora com base na anterior contabilização de 95 números e 448 reportagens pelo que certamente haverá uma ligeira discrepância nestes números.
} 
atualidade dos números é quase sempre duvidosa, sendo a distância entre a captura dos acontecimentos em película e a sua exibição quase sempre de várias semanas (ou, mesmo, de alguns meses); segundo, porque a mensalidade era um fator que, como já referi, raramente foi cumprido; terceiro, porque o termo revista pressupõe um critério jornalístico, coisa que o Jornal Português não teve nem fez, já que o interesse geral prendia-se com as inaugurações de obras públicas, as operações militares, as condecorações, manifestações de apoio a Salazar, exposições de carros e flores e demais "acontecimentos de interesse nacional" - assumida propaganda como afirmava o órgão administrativo e financiador do jornal, SPN/SNI. Todas estas justificações fazem parte do referido relatório de Correia de Mattos.

Posto isto, interessa-me destacar das palavras do diretor da Cinemateca Portuguesa - Museu do Cinema, José Manuel Costa, que no livrete da edição, num pequeno artigo intitulado $O$ Jornal como fonte de história - Cinco notas a propósito da edição do Jornal Português em $D V D$, lança duas linhas que me serviram de eixo condutor para este artigo: 1) "A série fala-nos hoje a vários níveis e que é como quem diz entre o retrato geral do regime através daquilo que ele quis mostrar de si e o plano aproximado dos eventos específicos, das pessoas e dos momentos que a película conservou em imagens em movimento e que a voz do narrador deixou fixada; 2) "n[a] área de disponibilização arquivística (...) [consideramos] que nos cabe abrir a porta do conjunto do acervo, convidando cada utilizador a escolher o seu caminho" (Costa 2015). Este é, portanto, um artigo que opta por encontrar o "seu caminho" dentro do "conjunto do acervo" através daquilo que ele tem de micro ("as pessoas e [os] momentos que a película conservou" e os "eventos específicos"). A análise que se segue não toma em consideração as mais de 16 horas de Jornal Português, limitando-se a cerca de 20 minutos espalhados por vários números ao longo dos vários anos da revista ligados por um elemento comum: o cinema. Assim, o propósito deste artigo passa por analisar de que forma foi o cinema representado no Jornal Português (algo que creio não ter ainda sido feito, muito menos com esta extensão), elencando para isso os representantes (e os representados) do cinema e de que modo estes quiseram ou souberam instrumentalizar (pessoal, contabilística ou propagandisticamente) aquela que foi a "arte com maior destaque" no jornal de atualidades (Piçarra 2006, 162).

Assim sendo, fazem parte desta análise 15 reportagens cujas informações principais se encontram na Tabela 1 e que se pode organizar em 5 categorias que analisarei de forma sistemática pela ordem seguinte: visitas de vedetas (7), rodagens (3), prémios do SNI (2), estreias de gala (2) e outros (1). Nesta última, incluo a reportagem mais heteróclita, "No Terreiro do Paço - O Contrato Colectivo da Distribüição [sic] de Filmes".

A escolha destas 15 reportagens pareceu-me natural pois em todas se tratam de momentos diretamente relacionados com a feitu- 
ra, a exibição ou o laureio de filmes ou, por sua vez, são reportagens que acompanham figuras da cinematografia nacional e mundial que (nalguns casos) "influenciaram" os caminhos do cinema português (sobre isso discutirei mais adiante).

Tabela 1: Reportagens do "Jornal Português" relacionadas com cinema

\begin{tabular}{|c|c|c|c|c|c|c|}
\hline N. & $\begin{array}{c}\text { Data de } \\
\text { Estreia }\end{array}$ & $\begin{array}{l}\text { Posicio- } \\
\text { namento }\end{array}$ & $\begin{array}{l}\text { Minuto } \\
\text { de início }\end{array}$ & $\begin{array}{l}\text { Minuto } \\
\text { de fim }\end{array}$ & Duração & Título \\
\hline 8 & $27 / 04 / 1939$ & $8 / 8$ & $6 " 55$ & $8 " 45$ & $1 " 50$ & $\begin{array}{c}\text { “Cinematografia Nacional” [rodagem de Feitiço do } \\
\text { Império] }\end{array}$ \\
\hline 11 & $13 / 10 / 1939$ & $7 / 7$ & $8 " 50$ & $9 " 46$ & $0 " 54$ & “Annabella e Tyrone Power em Lisboa" \\
\hline 12 & $21 / 12 / 1939$ & $3 / 8$ & $2 " 38$ & $3 ” 29$ & $0 ” 51$ & $\begin{array}{c}\text { "Vedetas do Cinema em Lisboa" [Simone Simon, Jan } \\
\text { Kiepura, Marta Eggerth] }\end{array}$ \\
\hline 13 & $07 / 02 / 1940$ & $3 / 6$ & $4 " 50$ & $5 " 32$ & $0 " 42$ & $\begin{array}{l}\text { "Vedetas do Cinema em Lisboa" [Robert Montgome- } \\
\text { ry] }\end{array}$ \\
\hline 17 & 29/06/1940 & $6 / 12$ & $5 " 28$ & $6 " 40$ & 1 "12 & $\begin{array}{c}\text { "Uma Estreia de Gala" } \\
\text { [estreia de Feitiço do Império] }\end{array}$ \\
\hline 25 & $27 / 03 / 1941$ & $1 / 5$ & $0 ” 23$ & $3 " 35$ & $2 " 12$ & $\begin{array}{c}\text { "Lisboa, Porta da Europa e os Que a Visitam: Wendie } \\
\text { Wilkie, Laurence Olivier e Vivien Leigh, Garcia } \\
\text { Viñolas, Josephine Baker" }\end{array}$ \\
\hline 27 & $03 / 07 / 1941$ & $6 / 9$ & $8 ” 09$ & $8 ” 37$ & $0 ” 28$ & "O actor Loius Jouvet em Lisboa" \\
\hline 28 & $17 / 09 / 1941$ & $3 / 5$ & $3 ” 25$ & $4 " 50$ & $1 ” 15$ & “Lilian Harvey em Lisboa” \\
\hline 34 & $06 / 11 / 1942$ & $4 / 5$ & 4 "06 & $5 " 45$ & 1 '39 & "Danielle Darrieux em Santarém" \\
\hline 45 & $26 / 05 / 1944$ & $3 / 7$ & $2 " 25$ & $4 " 22$ & $1 " 57$ & $\begin{array}{l}\text { "Um Grande Filme Histórico Espanhol” [Vésperas } \\
\text { Imperiais"/"El doncel de la reina" - notícia cedida } \\
\text { pelo NO-DO ao JP] }\end{array}$ \\
\hline 46 & $11 / 07 / 1944$ & $2 / 6$ & $2 " 31$ & 3"32 & $1 ” 11$ & $\begin{array}{c}\text { "No Pôrto, Um Torneio Medieval para o filme 'Inês } \\
\text { de Castro' " }\end{array}$ \\
\hline 48 & $02 / 09 / 1944$ & $2 / 8$ & 1 "'22 & $2 " 27$ & 1 '”05 & $\begin{array}{c}\text { "No Terreiro do Paço - O Contrato Colectivo da } \\
\text { Distribuição de Filmes" }\end{array}$ \\
\hline 61 & 04/10/1946 & $8 / 8$ & 8"46 & 10”07 & $1 ” 21$ & $\begin{array}{c}\text { "Entrega dos Prémios Cinematográficos do SNI" } \\
\text { [1944/1945] }\end{array}$ \\
\hline 63 & $16 / 11 / 1946$ & $2 / 5$ & $1 " 50$ & $3 " 25$ & 1 "'35 & $\begin{array}{c}\text { "Cinema Português - A Estreia de Gala do Filme } \\
\text { "Camões'” }\end{array}$ \\
\hline 73 & $13 / 02 / 1948$ & $4 / 6$ & $5 ” 07$ & $6 " 39$ & $1 ” 32$ & “A distribuição dos Prémios de Cinema” [1946] \\
\hline \multicolumn{2}{|c|}{ Valores médios } & 0.6 & $4 " 36$ & $5 " 56$ & 1 '”20 & \\
\hline
\end{tabular}




\section{O Jornal Português, a Política do Espírito e o cinema entre os dois}

Antes de uma análise mais pormenorizada destas 15 reportagens, é importante adotar uma perspetiva macro (o "retrato geral do regime através daquilo que ele quis mostrar de si”) para mais facilmente poder encarar e compreender algumas destas reportagens no seu momento histórico e assim mais facilmente perceber de que forma foi o Jornal Português uma ferramenta de propaganda para o SPN/SNI e de afirmação e autopreservação para António Lopes Ribeiro, o seu supervisor técnico a quem cabia, juntamente com a Sociedade Portuguesa de Actualidades Cinematográficas $\left(\mathrm{SPAC}^{4}\right)$, sob a alçada do SPN/SNI, decidir o que reportar. A favor desta última hipótese há que notar que Lopes Ribeiro foi realizador não creditado da grande maioria dos números, autor do texto narrado, ocasional leitor da voice over - juntamente com Augusto Pinto e Pedro Moutinho (Piçarra 2006, 168) - e por vezes figura central das próprias reportagens.

Os primeiros anos do Estado Novo foram regidos por uma contradição, uma "ambiguidade essencial, e deliberada, do Salazarismo" (Loff, 2015), que, como escreve o historiador Manuel Loff a propósito da edição em DVD no jornal Público, tanto desejava um regresso à tradição e aos costumes rurais, numa vertente nacionalista que procurava refundar a nacionalidade pela sua origem histórica (a insistência na reinvenção do passado, na política da memória, na reescrita histórica que tanto colocou os pés do Infante D. Henrique nas pedras bentas de Sagres como encontrou um antepassado do Presidente do Conselho nos Painéis de São Vicente de Fora) e folclórica (o SPN/SNI, sob a mão de António Ferro e a sua Política do Espírito ${ }^{5}$, foi particularmente hábil em encenar rituais modernos, construindo mitos de portugalidade), como por outro lado era "moderno nos meios e nas estratégias" (com a propaganda cinematográfica à cabeça, mas igualmente a reformulação urbana da capital ou a construção de uma classe alta, burguesa, urbana e cosmopolita, espectadora assídua dos jornais e das revistas semanais). Assim, desejava-se um "homem novo" (Rosas 2001, 1049) pelo regresso às origens através dos meios modernos.

\footnotetext{
${ }^{4}$ Há que esclarecer que, segundo Lopes Ribeiro na sua "autobiografia", a "SPAC sucedera à Agência de $\mathrm{H}$. da Costa", agência de distribuição e produção de filmes fundada em 1930 com sede em Lisboa e Madrid e que produz a primeira longametragem de Lopes Ribeiro, Gado Bravo (Ribeiro 1983, 31-32; 37; 39). Por morte do seu amigo (com quem fizera parte da sua viagem pelos estúdios da Europa), a empresa fica a cargo de Francisco Correia de Mattos (cujo relatório aqui cito frequentemente) e sua irmã, e viúva de H. da Costa, Luísa C. de Mattos, com quem António Lopes Ribeiro vem a casar em 1941.

${ }^{5}$ Expressão utilizada por António Ferro para designar a política cultural e de propaganda do Estado Novo. Ou, como o põe Fernando Rosas, "uma orientação oficial para a cultura e as artes, explicitamente destinada a 'educar o gosto dos Portugueses' no culto de valores estéticos e ideológicos modelares, apresentados e divulgados pela propaganda do Estado, a cargo do Secretariado de Propaganda Nacional (SPN)" (Rosas 1994, 282).
} 
O cinema era também espelho destas contradições, "o cinema português desta época e o que se lhe há-de seguir está cheio de paradoxos" (Torgal 2009, 186), um espelho evidente desta contradição no Jornal português é a reportagem "Danielle Darrieux em Santarém” em que a atriz do cinema europeu (e também de Hollywood, apesar da curta passagem) - figura certamente marcante para uma população urbana que ia ao cinema regularmente - é recebida em apoteose por campinos e jovens saloios da cidade ribatejana, "claro sinal de que o cinema e os seus ídolos podem contar com a fidelidade entusiástica da nossa juventude" (JP n. $\left.{ }^{\circ} 34\right)$.

No entanto, o conjunto das 15 reportagens pendem essencialmente para a modernidade que o cinema representava, para a construção do mito das estrelas do cinema português e para a apresentação da cidade de Lisboa como eixo central da cultura mundial e do cinema em particular. Isto para dizer que o conjunto das 15 reportagens não é de forma alguma representativo do conjunto que forma o Jornal Português nas suas mais frequentes preocupações temáticas ou propagandísticas.

Ainda no âmbito da Política do Espírito de António Ferro que o SPN/SNI espelhava, há que recordar, como afirma Paulo Cunha também no Público a propósito da edição do Jornal Português, "o SPN tornar-se-ia numa eficaz e implacável máquina de doutrinação ideológica do regime" (Cunha, 2015) que organizaria várias iniciativas culturais como o Cinema Ambulante, o Teatro do Povo, o Concurso da Aldeia Mais Portuguesa de Portugal, a companhia Verde Gaio, a marcante Grande Exposição do Mundo Português e, claro, o Jornal Português. Assim, o cinema para o SPN na década de 1930 é um ser de três pernas que, além do Cinema Ambulante e do Jornal Português, caminha ainda com a terceira perna dos filmes de fundo produzidos por este secretariado: A Revolução de Maio (1938) e Feitiço do Império (1940), ambos realizados por António Lopes Ribeiro, "um dos maiores cineastas do tempo" (Torgal, 2009, 177).

A década de 1940 apresenta-se como uma de mudanças significativas na importância dada ao cinema em Portugal pelo regime. Por um lado, os filmes de fundo de propaganda não haviam obtido o sucesso desejado, gorando assim os desejos de Lopes Ribeiro de um cinema de propaganda financiado pelo estado; por outro, a influência de Ferro junto de Salazar decai (e com ela a proteção dada ao cinema), até que este é forçado a sair do SNI, em 1949. Deste modo, o SNI, mas também a Agência Geral das Colónias, o Ministério do Trabalho e outros órgãos oficiais, passam a financiar esporádica e indiretamente obras produzidas por empresas privadas, nomeadamente as Produções Lopes Ribeiro que tentaram uma produção contínua em 1941.

A juntar a isto há também a necessidade de encontrar financiamento através de coproduções (especialmente com Espanha e com 
o Brasil) como resultado do que já havia sido tentado na década anterior em resultado das parcerias com as cinematografias dos fascismos europeus (Pereira 2013, 136-137). Todas estas experiências resultaram de pouco sucesso e confirmam a falência da "geração de 1930" (António Lopes Ribeiro, Leitão de Barros, Jorge Brum do Canto, Chianca de Garcia), que vai sendo progressivamente substituída pela geração seguinte de realizadores que haviam sido assistentes dos primeiros (i.e. Henrique Campos, Perdigão Queiroga, Augusto Fraga, Constantino Esteves), substituição essa que tem no dito "ano zero"6, em 1955, uma espécie de momento de viragem definitivo.

Por tudo isto, não é surpreendente que a última reportagem do Jornal Português relacionada com cinema date de fevereiro de 1948 quatro anos antes do final das atualidades, algo que condiz com a afirmação de Maria do Carmo Piçarra sobre o ligeiro câmbio temático do jornal que, após a Segunda Guerra, "perde a vertente ideológica acentuada de outrora e, no novo espírito da época, dá maior enfoque a notícias de economia" (Piçarra 2015, 11).

Ainda assim há que ter em conta que o Jornal Português não teve "um modelo estável de apresentação das notícias" (Piçarra 2015, 10), isto é, nem estrutura da pirâmide invertida típica do modelo anglo-saxónico em que se abria com as notícias mais importantes, nem estrutura de pirâmide, em que se construíam as atualidades no sentido de um desfecho apoteótico, típico do modelo germânico. No entanto, não deixa de ser evidente que a média das reportagens sobre cinema se situe na segunda metade dos respetivos números, sendo mesmo a última notícia por três vezes e só por uma vez abrindo o noticiário (caso de "Lisboa, Porta da Europa e os Que a Visitam: Wendie Wilkie, Laurence Olivier e Vivien Leigh, Garcia Viñolas, Josephine Baker," que ganha importância pelo agrupamento e pela introdução de Wendie Wilkie, candidato derrotado à presidência dos EUA).

Apesar de as reportagens relacionadas com cinema se distribuírem de igual modo entre a primeira metade e a segunda, é certo que o seu papel é secundário e em média iniciam-se só depois da marca dos 4 minutos. Note-se também que, das 15 reportagens, apenas 3 não se passam em Lisboa, sendo que uma delas foi cedida pelo jornal de atualidades espanhol, Noticiarios y Documentales (NO-DO), o que reflete também a precariedade dos meios de produção que, como o referido relatório explica, eram "diminutos" (Mattos, 1951, 31) - ao ponto de que, ao longo de 13 anos de atividade, só os salários dos operadores tenham sido atualizados, sendo, ainda assim, "muito inferiores aos que

\footnotetext{
${ }^{6} \mathrm{Na}$ história do cinema português estabeleceu-se o ano de 1955 como um "ano zero" por nesse ano não se ter estreado qualquer longa-metragem de produção nacional. No entanto, tem-se revisitado a "estrutura narrativa dominante" (Cunha 2016, 36), contestando-se a nulidade do ano de 1955 já que se produziram 99 metragens "inferior[es] a 1000 metros de película ou com menos de 60 minutos de duração" (idem) e houve grande atividade cineclubista e no meio da crítica.
} 
auferem por outros trabalhos" (idem). O centro 'noticioso' do Jornal Português era, portanto, Lisboa. Como refere Piçarra, a gestão do Jornal Português "esteve mais sujeita a critérios economicistas quanto à sua oportunidade para a promoção dos acontecimentos do regime do que a objetivos estritamente jornalísticos”.

\section{"Vedetas do Cinema em Lisboa"}

Se em geral é muito difícil ou impossível estabelecer de que forma uma audiência recebeu certo filme, perceber de que forma receberam os espectadores nacionais os números do Jornal Português é particularmente difícil. Por um lado, porque a sua exibição não era obrigatória e como tal só alguns cinemas do país exibiam a série e, por outro, mesmo exibindo-a, certo é que não era esse o chamariz da sessão, ou como o põe João Bénard da Costa, em entrevista a Maria do Carmo Piçarra:

Vistos hoje esses jornais de actualidades têm um carácter mais parecido com os dos fascismos europeus mas a eficácia daquilo (...) deveria ser bastante reduzida porque não era propriamente isso que ia provocar uma adesão entusiástica ao regime das pessoas que estavam na sala para ver o filme de fundo que não tinha nada a ver com aquilo (cit. Piçarra 2011, 131).

Se o argumento me parece válido, no caso das reportagens de cinema dificilmente se aplica, uma vez que o espectador de uma sala de cinema tende a interessar-se por cinema, assim, se as atualidades se reportam ao mundo das estrelas de Hollywood ou do cinema europeu parece-me que o envolvimento do espectador tenderá a ser mais fácil. Além disso, o Jornal Português visava especialmente um público urbano e cultivado já que, como esclarece Piçarra, "género híbrido entre o cinema e a imprensa, parece não ter sido um veículo ideal para a propaganda no mundo rural. (...) O Jornal Português optou antes por mostrar ao público urbano a vida rural estetizada pelo SPN/SNI” (Piçarra, 2015, 9-10).

Estou em crer que os "assuntos" de cinema tinham uma função que, sendo secundária (por neles não se fazer uma propaganda direta ao regime), funcionavam também de duas outras formas: por um lado, ajudavam a preencher os dez minutos que não raras vezes eram penosos de encontrar, já que, como explica Correia de Mattos, "a frequência dos assuntos que se torna indispensável recolher em imagens não se regista com regularidade[;] (...) é superior nos meses de bom tempo, decrescendo nos meses de inverno" (Mattos, 1951, 32), assim que a visita de uma celebridade ou a entrega de prémios, não sendo assuntos presos à atualidade, podiam ser reservados para esses momentos de maior carência "noticiosa". Além disso, as visitas das vedetas a Lisboa compunham uma reportagem recorrente (e independente das épocas do ano) no período da Segunda Guerra em que, 
como se sabe, o porto de Lisboa e o famoso Clipper $^{7}$ Lisboa-Nova Iorque traziam à cidade grandes figuras do cinema. Por outro lado, os "assuntos" de cinema colocavam Lisboa como capital cultural da Europa, uma Europa em crise por causa da guerra, passando uma imagem da cidade simultaneamente cosmopolita e espaço de paz e harmonia num continente conturbado. Tendo em conta o tom propagandístico da narração é, ainda assim, possível descobrir, nas entrelinhas, referências à situação política europeia e ao respetivo posicionamento português: na reportagem dedicada à passagem de Jan Kiepura refere-se que o "cantor de linda voz, o intérprete feliz d' 'A Boémia', [está] de jornada para os Estados Unidos em missão de angariar fundos para os refugiados da Polónia" (JP n. ${ }^{\circ}$ 12), já em 1941 na reportagem "Lisboa, Porta da Europa e os Que a Visitam", ouve-se: "Desde que a Guerra tornou inseguros os demais portos europeus, Lisboa ganhou foros de grande encruzilhada mundial. Pelo mar, pela terra e pelo ar, cruzam-se na nossa capital os viajantes mais famosos e os mais diversos" (JP n. ${ }^{\circ} 25$ ).

Outro aspeto recorrente destas reportagens dedicadas a estrelas do cinema de passagem por Lisboa é o tom apaixonado e encantado da narração que Piçarra classifica como "ligeira, mundana e a fazer humor fácil" (Piçarra 2012, 38), pois note-se: "Danielle Darieux, vedeta número um do cinema francês, a parisiense inconfundível, a francezinha-tipo" ( $J P$, n. $\left.^{\circ} 34\right)$, "encantadora e encantada, sorri de contentamento" (Idem.); "o grande ator Francês Louis Jouvet, que todos conhecem do cinema, mas que é maior ainda no teatro" ( $\left.J P,{ }^{\circ}{ }^{\circ} 27\right)$; numa das poucas reportagens a ser vendida para um jornal de atualidades estrangeiro, o Metro Journal de Paris (Mattos 1951, 41). Ou ainda Marta Eggerth, "estrela de primeira grandeza com nome marcado a letras de ouro no livro de honra do cinema" (JP, n. $\left.{ }^{\circ} 12\right)$.

Mas talvez o caso mais surpreendente seja a reportagem "Lilian Harvey em Lisboa," em que a atriz, após ter sido obrigada a sair da Alemanha, em 1939, e a perder a sua fortuna, que fora confiscada pelas autoridades Nazis, passa por Lisboa a caminho de Los Angeles com o seu "sorriso célebre" (JP n. ${ }^{\circ}$ 28) e com grande "gracilidade" (idem).

Sirvo-me destes casos para argumentar que, embora houvesse um motivo propagandístico nestas reportagens sobre a passagem por Lisboa de grandes vedetas, é certo que muitas delas resultavam também de um embeiçamento de António Lopes Ribeiro e António Ferro pelo universo das estrelas de cinema estrangeiro. A esse respeito, Piçarra afirma que a reportagem sobre a vinda de Lilian Harvey "trai [o estilo da revista cinematográfica, com] o deslumbramento do diretor do Jornal Português e do diretor da propaganda pelas vedetas" (Piçarra 2012, 40), já que a reportagem apresenta António Lopes Ribeiro e Gui-

\footnotetext{
${ }^{7}$ Aeronave para viagens de longa distância de nome completo Boeing 314 Clipper produzida pela referida Boeing Airplane Company entre 1938 e 1941.
} 
lherme Pereira de Carvalho a passearem com a atriz pelos jardins de Monserrate. De forma idêntica, também a passagem por Lisboa de Laurence Olivier e Vivien Leigh é assim descrita pelo narrador:

passaram por Lisboa, também a caminho de Londres, duas celebridades cinematográficas que eram aguardadas no cais por grande número de jornalistas da especialidade e pelos representantes da United Artists, Vivien Leight e seu marido Laurence Olivier (...) [que se] mostraram da mais cativante amabilidade diante dos curiosos perguntadores. No próprio dia da chegada, assistiram à estreia em Portugal de Rebecca, o filme que ganhou a Taça do Animatógrafo de 1940 (JP, n. $\left.{ }^{\circ} 25\right)$.

Ou seja, a propaganda, a cinefilia e os interesses pessoais de Lopes Ribeiro encontram-se nestas reportagens dedicadas às estrelas de cinema estrangeiras, já que o Jornal Português apresenta Lisboa como espaço de paz e calma numa Europa conturbada, ao mesmo tempo que dá destaque a um evento organizado por António Lopes Ribeiro - uma vez que ele era diretor, editor, redator e proprietário da revista Animatógrafo, a cujo galardão a narração faz referência.

Outro momento de semelhante fascinação pelas estrelas de Hollywood dá-se aquando da passagem de Annabella e Tyrone Power por Lisboa, em que Teresa Cabral se vê descalça porque oferece os seus sapatos à atriz francesa que os "admirara e apetecera" (JP n. ${ }^{\circ}$ 11). Assim, vários números do Jornal Português destes anos de guerra parecem antecipar e continuar o universo mítico da Lisboa do final de Casablanca ${ }^{8}$.

Também António Ferro era cinéfilo tendo visitado the place where dreams are made, e relatado a experiência no livro Hollywood, capital das imagens ${ }^{9}$ (1931), onde se evidencia o seu fascínio pela indústria cinematográfica norte-americana. Daí a atenção dada ao cinema pelo SPN/SNI, os apoios diretos, as isenções de impostos, os empréstimos, os subsídios, e a própria criação dos prémios SNI, algo que Ferro fez questão de lembrar em 1949, no seu último discurso, antes da demissão (Pereira 2013, 131).

\footnotetext{
${ }^{8}$ Lisboa essa que o cinema não se esqueceria de representar, mesmo que em estúdio, com fados abrasileirados por Carmen Miranda em The Conspirators (1944), que continua o enredo do original na nossa capital. Também o cinema português retratou este período em Passagem por Lisboa (1995), de Eduardo Geada, cheio de espiões e vedetas internacionais e, claro, o personagem de António Lopes Ribeiro.

${ }^{9}$ Neste livro, Ferro refere-se às newsreels do seguinte modo: "As 'Atualidades Gráficas', verdadeiro cinema puro, não estão à altura da sua função. Cumprem mal, tarde e a más horas, o seu papel de jornalismo quotidiano... A 'Atualidade Gráfica', para ser impressiva, para ser flagrante, para ser 'atualidade' e 'gráfica', deve ter algo de reportagem viva dum jornal, a frescura e a dinâmica da notícia colhida e logo escrita" acrescentado adiante que estas "não se devem limitar, portanto, a copiar os acontecimentos, a registá-los, mas a surpreendê-los, a provocá-los às vezes..." (Ferro, 1931). O Jornal Português participa, como já referi, do primeiro erro. No entanto, o trabalho de criar notícias é coisa que, não fazendo diretamente, acontecia com as sistemáticas reportagens sobre os eventos organizados pelo SPN/SNI ou com a elevação de fait divers ao estatuto de notícia nacional.
} 
A ideia de que havia uma potencialidade de internacionalização ibero-latina para um cinema Português vinha de Ferro, mas também de António Lopes Ribeiro, que acreditou que, com a carência de película e as dificuldades de distribuição do cinema americano na Europa, se havia criado a oportunidade há muito aguardada para um cinema português de sucesso ibero-latino. Com o avançar da guerra, esta ideia ainda mais se cimenta por toda a cinematografia europeia estar num impasse e todos os filmes do pós-guerra serem necessariamente muito pobres em meios: era o momento para o cinema de qualidade português, os grandes filmes históricos (Ribeiro, 2014).

Este projeto resulta em parte das visitas das vedetas. É o próprio Lopes Ribeiro que, na sua "autobiografia”, escrita para o catálogo da Cinemateca Portuguesa em 1983, afirma: "Lilian Harvey, de passagem por Lisboa, foi madrinha dessa tentativa de produção contínua quando em 1941 se fundam as Produções António Lopes Ribeiro e se produz em menos de um ano Pai Tirano [1941], Pátio das Cantigas [1942] e Aniki Bobó [1942]" (Ribeiro 1983, 37). Mas, como cita Piçarra, também em 1940 passou por Lisboa, a caminho de Hollywood, Jean Renoir, como é referido no número de dezembro desse ano na revista Animatógrafo. A propósito de uma projeção de A Aldeia Mais Portuguesa de Portugal (1938), realizado por Lopes Ribeiro lê-se que:

O maior se não o único título de glória da nossa arte, declarou-nos, é a autenticidade. (...) Além disso, a beleza desconhecida para mim (...) das vossas paisagens, dos vossos trajes, da vossa arquitectura rústica, dão ao filme um sabor e um interesse que o torna projectável em toda a parte (cit. Piçarra 2011, 37).

Tendo Renoir acrescentado também que, do ponto de vista artístico (não tanto do ponto de vista económico), havia grande potencialidade num cinema latino com as características referidas. Este projeto de internacionalização ibero-latina do cinema português torna-se evidente quando António Ferro expõe a Salazar o "Plano para uma campanha de propaganda em toda a América e no Brasil em particular" em 1942, após uma viagem pelo Brasil e América do Sul (ANTT - Arquivo Salazar, 1942, 25).

Deste modo, as reportagens das vedetas em Lisboa não só funcionaram como simples objeto de propaganda interna, passando a imagem de um Portugal "oásis de paz num mundo de guerra" ( $J P$ n. ${ }^{\circ}$ 34), como refere o narrador em "Danielle Darrieux em Santarém", mas também revelam um fascínio dos diretores do Jornal Português pelas estrelas estrangeiras, na esperança de criar em Portugal uma indústria cinematográfica através dos conselhos e contactos estabelecidos e do aproveitamento pessoal de Lopes Ribeiro para a valorização da sua carreira como realizador, produtor e crítico de cinema. Não esquecendo o tom propagandístico da narração, não deixa, no entanto, de ser sintomático (pelo menos como desejo), que a reportagem de "Lilian Harvey em Lisboa" termine com a afirmação, "mas Lilian prometeu voltar e até interpretar um filme em Portugal". 
Este projeto de internacionalização ibero-latina acaba por não ir avante com o impasse na Política do Espírito após o afastamento de António Ferro.

\section{A agenda ibérica de António Lopes Ribeiro e o sonho de uma in- dústria cinematográfica}

No seu texto sobre a edição em DVD para o jornal Público, o historiador de cinema Paulo Cunha explica que o "cinema (...) serviu e serviu-se do Estado Novo, prestando-se como a máquina de propaganda de massas em troca de proteção e dos favores de António Ferro", acrescentando adiante que a "figura de Lopes Ribeiro confunde-se com o próprio jornal de actualidades" (Cunha, 2015). Por transitividade, pode dizer-se que António Lopes Ribeiro se serviu do regime para poder fazer cinema. Aliás, a expressão que Piçarra e Cunha usam várias vezes, em diversos textos, é "as actualidades de Lopes Ribeiro" referindo-se certamente à referida supervisão técnica, mas também à instrumentalização do Jornal Português pelo cineasta.

De facto, quando Maria do Carmo Piçarra entrevistou João Bénard da Costa, perguntou-lhe: "Até que ponto a amizade do Lopes Ribeiro e do Ferro não foi o motor de uma carreira que de outra forma talvez não tivesse tanta dimensão?”; ao que o então diretor da Cinemateca Portuguesa respondeu: "Isso com certeza" (cit. Piçarra 2011, 136).

António Lopes Ribeiro foi, de facto, um dos primeiros a desejar um cinema de propaganda à imagem do que se vinha fazendo pelos regimes ditatoriais europeus, como deixou claro na revista Kino, logo em 1930: "utilizar o fonocinema para fins de propaganda é, quanto a nós, uma necessidade urgente” (cit. Piçarra 2006, 108).

Outro dado que contribui para confirmar esta especial atenção a António Lopes Ribeiro passa pela conhecida desavença com Leitão de Barros (e também com Chianca de Garcia), quando, em meados dos anos 1930, se atacam mutuamente na revista Bandarra a propósito dos filmes de então de cada um, nomeadamente, Gado Bravo (1934) e As Pupilas do Sr. Reitor (1935) (Félix, 1983, 344). A leitura de Bénard da Costa sobre esta zanga é a de que Lopes Ribeiro se queria apresentar como mais vanguardista que Barros (cit. Piçarra 2006, 136-137), então o cineasta da preferência de António Ferro, que lhe chamou "o primeiro realizador português com olhos do nosso tempo" (cit. Pereira 2013, 122). Talvez o argumentário escrito tenha resultado ou o facto de Lopes Ribeiro ter realizado um inaudito making of avant la lettre, A Preparação do filme 'Gado Bravo' (1933). Certo é que a campanha terá surtido efeito, já que, segundo a "autobiografia” de Lopes Ribeiro, António Ferro tê-lo-á convidado para Chefe da Secção de Cinema do SPN e Lopes Ribeiro terá recusado por considerar "não ter vocação para funcionário público" (Ribeiro, 1983, 39). 
Um outro dado importante prende-se com as campanhas de opinião feitas em revistas de especialidade como a Animatógrafo (da qual Lopes Ribeira era, como referido, diretor, editor, redator e proprietário) a favor de um apoio direto do estado na cinematografia nacional. Em particular, no editorial da Animatógrafo, "O Cinema Português perante o Chefe", Lopes Ribeiro "recorda" Salazar de que o cinema "pode levar a toda a parte a sua Lição [sic] e o nosso Exemplo [sic]", solicitando-lhe que "não desampare a Cinematografia Portuguesa” (cit. Piçarra 2011, 82).

Há então que perceber de que forma António Lopes Ribeiro exerceu a sua influência no Jornal Português, sendo natural que as reportagens relacionadas com cinema, em particular aqueles em que ele surge como personagem ou que versam sobre filmes da sua safra, são o exemplo mais direto desses intentos.

Começo primeiro pelas três rodagens das quais se fizeram reportagens: a primeira é de Feitiço do Império, realizado pelo próprio Lopes Ribeiro; a segunda intitula-se "Um Grande Filme Histórico Espanhol" e foi cedida pelo NO-DO; a terceira trata da rodagem, no Porto, de Inês de Castro, filme realizado por Leitão de Barros e produzido pelo próprio Lopes Ribeiro.

A narração da reportagem "Cinematografia Nacional," dedicada à rodagem de Feitiço do Império, começa afirmando "Conhecer os chamados bastidores do cinema não é coisa, ainda que muito apetecida, ao alcance de toda a gente. Claro que o Jornal Português tem privilégios e pode fazer isso com certa facilidade" (JP n. ${ }^{\circ} 8$ ). Por um lado, começa-se logo por afirmar o lado de exclusividade das imagens que se estão vendo como momento irrepetível e único, só acessível a uma casta selecionada de portugueses (são vários os planos em que se vêm trabalhos com refletores, microfones, câmaras e demais técnicos especializados, assim como dois longos planos da protagonista do filme sendo maquilhada); por outro, atesta-se o poder do Jornal Português em aceder à notícia e aos circuitos mais restritos, sem nunca referir que tanto o realizador do filme em causa como o diretor do jornal e autor da narração são a mesma pessoa. Prossegue-se:

Procura-se igualmente, com o Feitiço do Império mais uma vez provar que a indústria cinematográfica portuguesa, sendo embora a quantidade dos seus trabalhos ainda reduzida, vai adquirindo com a sua qualidade, uma categoria superior que, senão atinge as expressões de produção dos grandes centros produtores universais, já ultrapassa nesse particular (...) aquelas de países mais ricos em recursos e número de habitantes e portanto com mais possibilidades, por mais vantagens, na exploração comercial desta indústria. (JP, n. ${ }^{\circ} 8$ )

Portanto, não só a reportagem afirma a qualidade de um filme que está ainda por terminar, como a apresenta como critério de comparação com outras cinematografias europeias. Assim, Lopes Ribeiro continua o intento de promover internamente a ideia de que seria possível implementar uma indústria de qualidade equiparável em 
Portugal, e a reportagem faz por afirmar que Feitiço do Império é mais uma pedra importante na construção dessa cinematografia portuguesa industrial e viável. Ou seja, usa-se do seu jornal de atualidades para justificar a produção do filme Feitiço do Império, para afirmar a sua (do filme e do próprio Lopes Ribeiro) importância no panorama da cinematografia portuguesa, e ainda como peça chave num projeto maior e mais ousado de industrialização e internacionalização.

Outro aspeto desta reportagem é o que afirma Feitiço do Império como filme de notória e assumida propaganda, "uma finalidade altamente pedagógica e patriótica, pois se destina à larga expansão (...) onde portugueses vivam e possam por ele ser informados das riquezas e belezas, sedutoras como nenhumas, das terras de Portugal de além mar" (idem). Atente-se no verbo "informar," associado a um filme de ficção. Como Matos-Cruz explica, o filme tem em igual proporção "apontamentos turísticos", "facetas de missionação", representa os "sinais de progresso", da intervenção do regime nas obras públicas e "é sem dúvida mais expressiva a dimensão estritamente documental" (Matos-Cruz 2012), não fossem as sequências documentais do filme resultantes da Missão Cinegráfica às Colónias chefiada por Carlos Selvagem, na qual António Lopes Ribeiro e o ator Luís Campos participaram, recolhendo várias imagens que integrariam os exteriores de Feitiço do Império. À semelhança de A Revolução de Maio (1937) - em que o cartão de abertura indica: "As imagens documentárias incluídas nêste [sic] filme são autênticas reportagens cinematográficas, filmadas sem qualquer artifício de encenação” -, que recorre às atualidades como dispositivo de aproximação a um real construído pela propaganda, também Feitiço do Império explora essa estratégia, revestindo-se de uma qualidade documental. Estas soluções narrativas acabam por refletir na ficção o trabalho de Lopes Ribeiro nas atualidades do Jornal Português.

Quanto à reportagem "No Pôrto [sic], Um Torneio Medieval para o Filme "Inês de Castro'” de 1944, dá-se conta de uma encenação de um torneio medieval nos jardins do Palácio de Cristal, onde vários figurantes, cavaleiros de capa e espada, cavalos e um touro aparecem. A reportagem é rápida em esclarecer que o realizador Leitão de Barros dirige o filme num estúdio de Madrid e que, "por ser a primeira vez que colaboram técnicos e artistas cinematográficos portugueses e espanhóis e pelo tema escolhido, a iniciativa revela-se de grande interesse e importância" (JP, n. ${ }^{\circ}$ 46). A importância foi tal que o filme foi considerado de interesse nacional em Espanha, algo que só acontecera três vezes antes (Félix 1983, 516). Inês de Castro foi a primeira coprodução entre Portugal e Espanha (apesar de tal facto não ser oficial, e ainda que já havia sido experimentado o sistema das duas versões com Bocage e Las Tres Gracias, também de Barros). Mas atente-se que a narração explica que, não só é de grande importância o método de produção, como o tema escolhido, a saber, o famoso romance entre D. Pedro e Inês de Castro, a dama de companhia da 
esposa do futuro rei, infanta Constança de Castela, que decorre no ano de 1334, altura de paz entre Portugal e Castela. Assim, tomo como minhas as palavras de Antonio Rodrigues quando especula que "não será delírio paranóico fazer uma leitura política de Inês de Castro, transpondo a aliança política entre Castela e Portugal para o período da realização do filme e a aliança entre as duas obscurantistas ditaduras ibéricas" (Rodrigues 2008).

Não será certamente aleatório que esta tenha sido uma das reportagens trocadas com o NO-DO e que a reportagem "Um Grande Filme Histórico Espanhol" (recebida em troca) seja igualmente sobre a rodagem de um filme histórico cuja ação decorre durante o reinado dos "Reis Católicos", Fernando e Isabel. A narração dessa reportagem começa exatamente com "De Espanha o nosso camarada NO-DO envia-nos esta reportagem de uma tomada de vistas exteriores para o filme espanhol Vésperas Imperiais". Assim, a "camaradagem" entre os jornais de atualidades traduzia-se na partilha de notícias, isto é, o cinema era instrumentalizado por ambas as máquinas de propaganda dos respetivos regimes para solidificar as relações ibéricas - e nesse processo alguns cineastas saíam beneficiados ${ }^{10}$.

É, no entanto, importante notar, mais uma vez, a reportagem do ano anterior, "Lisboa, Porta da Europa e os Que a Visitam", e destacar um dos visitantes, Garcia Viñolas. Manuel Augusto Garcia Viñolas era então diretor da Secção Nacional de Cinematografia em Espanha e diretor da revista de cinema Primer Plano. Ouve-se o narrador dizer:

Esperavam-no António Lopes Ribeiro, o diretor da revista Animatógrafo, e Fernando Fragoso, correspondente em Portugal do Primer Plano. Embora a sua viagem fosse puramente particular, Garcia Viñolas aproveitou para explorar o estreitamento das relações cinematográficas luso-espanholas que tanto ele como Lopes Ribeiro defendem com denudo (JP, n. ${ }^{\circ} 25$ ).

Assim, Lopes Ribeiro usa o Jornal Português para influenciar o seu homónimo espanhol na parceria que os beneficia a ambos e apre-

\footnotetext{
${ }^{10}$ A narração e os documentos oficiais referem o filme "Vésperas Imperiais" ou, no relatório de Correia de Mattos, "Visperas Imperiales"; no entanto, nenhum filme desses títulos consta na produção espanhola da época. Aliás, analisando a obra de Eusebio Fernández Ardavín, percebemos que nenhum filme seu estreia entre 1943 e 1946, sendo a reportagem de maio de 1944. No entanto o seu filme El donzel de la reina (1946) trata exatamente do período dos "Reis Católicos". Numa entrevista dada ao Primer Plano aquando da estreia, o realizador lamenta que tenha passado algum tempo desde que a película havia sido realizada (Palomar, 1946). Note-se que, sobre o seu filme, Ardavín explica que "os temas que exaltam os valores patrióticos atraem-me. Acredito que a principal orientação do cinema espanhol deve estar aqui, é uma produção com características rácicas" e acrescenta que deseja "um cinema nacional exaltador das nossas glórias". É, portanto, sintomático que a troca de assuntos de cinema entre os dois jornais se faça sobre rodagens de filmes da mesma temática e com a mesma intenção patriótica nacionalista, exatamente de acordo com as ideias de cinema de Lopes Ribeiro e Garcia Viñolas e respetivos órgãos superintendentes.
} 
senta-se como paladino das relações cinematográficas ibéricas. Repare-se que, ao longo dos vários números do Jornal Português, Lopes Ribeiro ora é realizador e/ou cineasta, ora é diretor do Animatógrafo, mas nunca supervisor ou diretor do Jornal Português, como se não houvesse conflito de interesses entre esses cargos e o pretenso jornalismo das atualidades. Repare-se também que o narrador frisa que a viagem foi "puramente particular", ainda que António Lopes Ribeiro também fizesse uma viagem a Madrid em 1942 com o mesmo propósito, pelo que seria entrevistado para a Primer Plano.

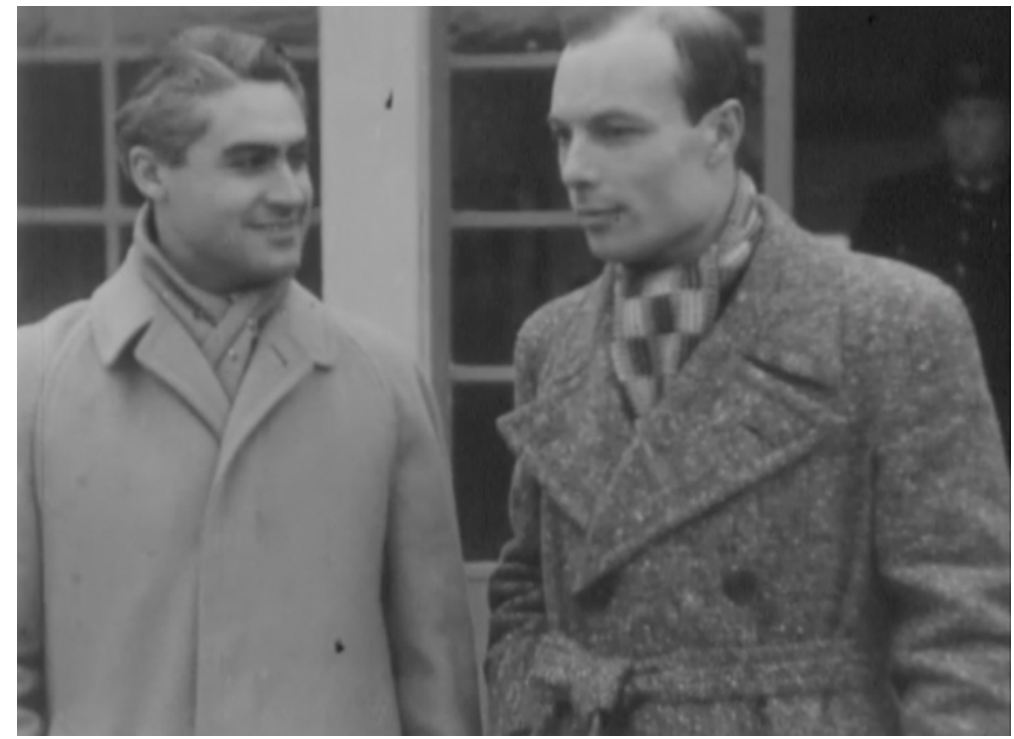

Imagem 1: Garcia Viñolas (à esquerda) e António Lopes Ribeiro (à direita) na reportagem "Lisboa, Porta da Europa e os Que a Visitam" no n. ${ }^{\circ} 25$ do Jornal Português Cinemateca Portuguesa - Museu do Cinema

Nessa entrevista, começa-se por afirmar que, "para o Primer Plano, o Animatógrafo é o mais íntimo camarada na tarefa e na missão de criar, respetivamente, um sentido e uma medida para as nossas cinematografias nacionais"11 e que António Lopes Ribeiro é a "singular encarnação pessoal do cinema português” (Primer Plano 1945). A entrevista prossegue: "é o homem que simboliza o que é e o que pode ser o cinema de Portugal no futuro" (idem). Mas o mais importante é, naturalmente, a questão do cinema ibérico e de lançar as bases para as coproduções entre Portugal e Espanha:

Também compreende Lopes Ribeiro que toda a manifestação cinematográfica, por mais perfeita que seja, nunca alcançará o ponto de maturação enquanto não ultrapassar os limites nacionais. É isto que urge ao nosso cinema, e é também a necessidade vital do cinema português (Nieves 1942).

O projeto de Lopes Ribeiro não se ficaria pelas coproduções com Espanha, aliás, ele di-lo na entrevista à Primer Plano. Quando perguntado sobre qual a próxima tarefa do cinema português, uma vez cimentado o intercâmbio ibérico, o realizador português respon-

\footnotetext{
${ }^{11}$ Todas as traduções desta entrevista são minhas, a partir do original em espanhol.
} 
de "a reconquista do mercado brasileiro" (idem), como já havia referido anteriormente.

Certo é que o relatório de Correia de Mattos dá conta de que em 1944 se estabelece o acordo com o NO-DO "por recomendação do SPN" e, portanto, a campanha de sensibilização para uma parceria cinematográfica ibérica de Ribeiro e Viñolas começava a surtir efeito.

No entanto, a presença de Viñolas é ainda mais profunda, no caso da reportagem sobre a rodagem de Inês de Castro. É que, se Leitão de Barros está creditado como realizador do filme, logo abaixo, nos cartazes espanhóis do filme, está o nome de Garcia Viñolas como diretor artístico. De novo no Primer Plano, há um artigo particularmente revelador desta direção bicéfala, intitulado "Los realizadores de "Inês de Castro' hablan de su colaboración", onde se encontram expressões como doblemando detrás de la cámara e dual colaboración diretriz. Aliás, o artigo refere Inês de Castro como o primeiro filme de Viñolas e, em declaração, Barros afirmou que "no guião, na orientação técnica, no conselho artístico pode dizer-se que a sua presença [de Viñolas] foi constante", acrescentando ainda que a película Inês de Castro é, na maior parte, Garcia Viñolas (Primer Plano, 1945). Assim, a presença subliminar do diretor da Secção Nacional de Cinematografia em Espanha e da revista Primer Plano no Jornal Português torna-se evidente, e percebemos que grande parte do projeto do cinema ibérico terá resultado da "relação estreita" entre ele e António Lopes Ribeiro.

Neste sentido, o caso da rodagem de "Um Grande Filme Histórico Espanhol” resulta do acordo de intercâmbio de notícias entre os dois jornais de atualidades e, como tal, justifica-se que esta seja um dos mais longos assuntos abordados, duração essa que não resulta numa narração mais longa ou aprofundada, sendo até essencialmente descritiva, acrescentando comentários sobre a natureza ingrata do trabalho em cinema, tudo ao som da épica abertura de Guillaume Tell, de Rossini.

\section{O cinema como evento social, os prémios do SNI e 'outros'}

A par das reportagens sobre as rodagens, há duas que também se debruçam sobre as estreias de gala de filmes portugueses: "Uma Estreia de Gala" [estreia de Feitiço do Império] e "Cinema Português - A estreia de Gala do Filme 'Camões”. Na primeira, o tom prende-se na vertente de evento social, ao qual ninguém faltou, "um notável acontecimento pela categoria e elegância da assistência. Os melhores nomes da política, das letras e das artes não faltaram ao sensacional espetáculo" (JP n. ${ }^{0}$ 17). Contabilizam-se as presenças de ministros e de "sua Excelência o Presidente da República". À chegada deste irrompe subitamente o hino nacional e todos os presentes saúdam, de braço em riste, o general Carmona. No segundo caso, e ainda que Camões tenha sido considerado um filme de "utilidade pública" e "interesse nacional" (Félix 1983, 410) e "patrocinado pelas entidades 
oficiais" ( $J P$, n. $\left.^{\circ} 63\right)$, nenhuma figura política de topo compareceu à estreia, sendo que "o senhor professor Caeiro da Mata, Ministro da Educação Nacional, representava o Chefe de Estado” (idem). É um pormenor importante, que revela a diferença do interesse pelo cinema dos chefes de estado no intervalo de 6 anos.

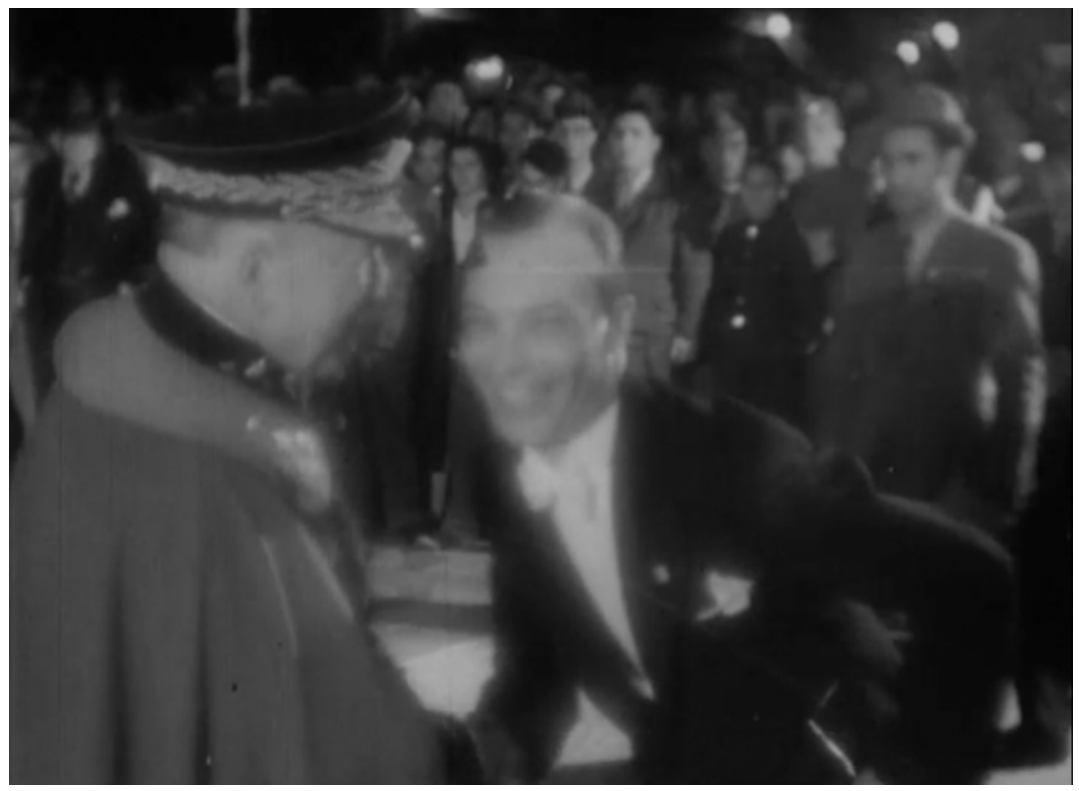

Imagem 2: Óscar Carmona (à esquerda) e António Lopes Ribeiro (à direita) na reportagem "Uma Estreia de Gala" no n. ${ }^{\circ} 17$ do Jornal Português Cinemateca Portuguesa - Museu do Cinema

Ainda que o tom da reportagem se mantenha no evento social, o regresso da abertura de Guillaume Tell e a triunfante voz do narrador acentuam a imponência do filme que "confirmou a excecional categoria que o seu notável tema impunha. O nosso povo conta, a partir de agora, com um grande espetáculo nacional, onde a figura do imortal épico renasce na sua moldura histórica para admiração dos portugueses de hoje" (JP n. ${ }^{\circ}$ 63). Ou seja, um filme que traduz a contradição, já referida, da Política do Espírito. Camões teve um resultado de bilheteiras muito abaixo do esperado funcionando de facto como o ponto final do projeto de Ferro na medida em que "Leitão de Barros foi também um dos alicerces das 'encenações populares nacionalistas' que o regime criou ou a que deu o aval, das marchas populares aos grandes desfiles, características de que Camões não deixa de ser um exemplo, ou o seu remate" (Ferreira 2006).

Com a conversão do SPN em SNI no pós-guerra, a estratégia de apoio a um cinema nacionalista afirmou-se em parte pela criação dos prémios cinematográficos, algo que o próprio António Ferro admite: "As intenções amplamente construtivas os nossos prémios são, portanto, facilmente compreensíveis. (...) Quem não concordar com tais princípios (...) só tem um caminho a seguir: não concorrer aos nossos prémios" (cit. Vieira 2011, 16).

O Jornal Português só reporta sobre as duas primeiras entregas de prémios (a primeira, que combinou os anos de 1944 e 1945, e a 
segunda, de 1946), algo que só poderá ser explicado pelo referido desvio temático que se dá no jornal com a saída de Ferro. Ambas as reportagens são preenchidas com quase ininterruptas ovações, sendo que António Lopes Ribeiro nas duas é galardoado mais que uma vez $^{12}$. Note-se, como o fez Luís Reis Torgal, que, na cerimónia referente a 1945, Ferro não cita no seu discurso os realizadores premiados apenas fazendo nota que eram "da velha guarda"13 (Torgal 2009, 194), em contrapartida, na cerimónia de 1946, Ferro trata de forma muito elogiosa Leitão de Barros (idem). A reportagem referente aos prémios de 1946 tem ainda a particularidade de destacar apenas um filme - Camões - quando a primeira não só elencava os prémios para melhor filme de ficção de longa-metragem como para melhor documentário e também os filmes a que correspondiam os prémios de interpretação. Além disso, apresenta a cerimónia como um evento restrito a que "assistiu um público muito escolhido" ( $J P$ n. ${ }^{\circ}$ 73) e deixa a sua homenagem a António Ferro, que proferiu "um oportuno e importante discurso" (idem). É de novo bem clara a intenção de conferir às reportagens do Jornal Português sobre cinema uma qualidade restrita, bem como a sua instrumentalização em benefício do seu supervisor.

Por fim, a categoria 'outros' que continha a reportagem heteróclita "No Terreiro do Paço - O Contrato Colectivo da Distribüição [sic] de Filmes". Esta reportagem deve ser vista como consequência de três fatores: 1) o corporativismo salazarista (não é acaso que o enquadramento escolhido seja tal que a fotografia de Salazar sobre a secretária do "Senhor Subsecretário de Estado das Corporações e da Providência Social" Trigo de Negreiros esteja quase sempre visível) como a narração refere, "mais uma vitória do corporativismo na harmonização das relações entre patrões e empregados"; 2) como resposta às greves que um pouco por todo o país surgiam em resultado das restrições que a Segunda Grande Guerra havia imposto; e 3) apesar de António Lopes Ribeiro já não ser Presidente do Sindicato Nacional dos Profissionais do Cinema à data da reportagem, fora-o entre 1938 e 1943 (Ribeiro 1983, 38), sendo portanto este momento também a concretização de um trabalho seu, como mais uma vez a narração dá a entender: "Os presidentes das direções, senhor Fernando Fragoso [Grémio Nacional da Distribuição de Filmes] e Simões de Sousa [Sindicato Nacional dos Profissionais do Cinema], leram discursos em que se historiaram as diligências feitas e se louvou o seu resultado" (JP, n. ${ }^{\circ} 48$ ). Aliás, na sua autobiografia, Lopes

\footnotetext{
${ }^{12}$ Pelo melhor documentário em 1944, Inauguração do Estádio Nacional, pelo melhor filme em 1945, A Vizinha do Lado (que a narração não esquece de referir tratar-se de uma produção SPAC), e em 1946, pela produção de Camões (note-se que na reportagem anterior não houve qualquer referência aos produtores dos filmes premiados).

${ }^{13}$ Sabe-se o horror de Ferro às comédias portuguesas e A Vizinha do Lado é um exemplo desbragado do género, mais ainda quando nesse ano concorria ao prémio o sério e histórico Inês de Castro.
} 
Ribeiro afirma mesmo, "celebrei contratos coletivos que muito beneficiaram os profissionais da exibição e distribuição" (Ribeiro 1983, 38), o que a reportagem confirma, já que a figura de Lopes Ribeiro surge no fundo de alguns planos, ainda que não seja mencionada a sua presença, nem lhe seja feita qualquer forma de destaque.

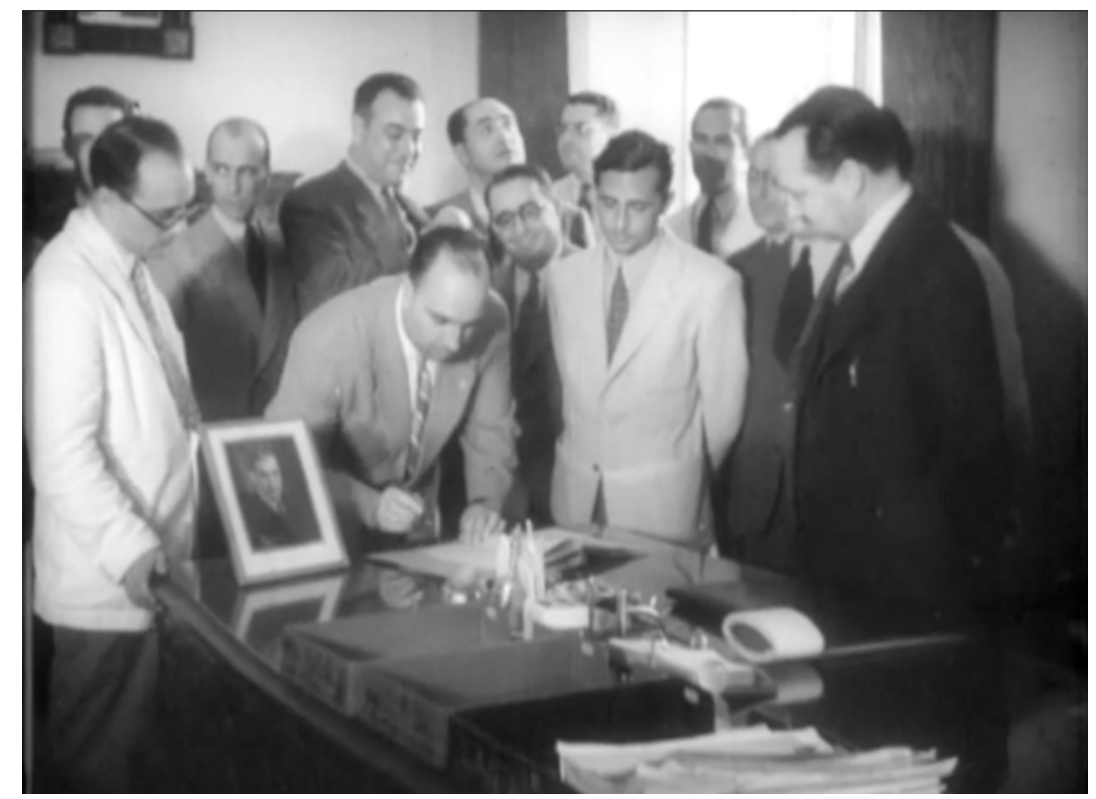

Imagem 3: António Lopes Ribeiro surge no fundo, o terceiro rosto a contar da esquerda, na reportagem "No Terreiro do Paço - O Contrato Colectivo da Distribüição de Filmes" no n. ${ }^{\circ}$ 48 do Jornal Português | Cinemateca Portuguesa - Museu do Cinema

Além disto, este primeiro contrato coletivo, que estabeleceu os salários mínimos e as condições de trabalho e que chamou à mesma mesa os que faziam cinema e os que o distribuíam e exibiam, é o primeiro passo para o Fundo do Cinema Nacional, que só seria legislado quatro anos mais tarde. $\mathrm{Na}$ sua autobiografia, Lopes Ribeiro refere a "influência" que teve "na redação da lei de proteção do cinema nacional" e acrescenta que participou no "grupo de trabalho que elaborou a lei 7/71 que criou o Instituto Português do Cinema” (Ribeiro 1983, 39). Mais uma vez, Lopes Ribeiro e a sua agenda para o cinema português manifestam-se numa reportagem do "seu" jornal de atualidades.

\section{Uma questão em aberto}

Neste artigo tentei mostrar que António Lopes Ribeiro, nas múltiplas funções que ocupou enquanto supervisor/diretor do Jornal Português, redator, editor e proprietário da revista Animatógrafo, realizador e produtor com as Produções Lopes Ribeiro, "adido" de António Ferro na cimentação de um cinema de "qualidade", paladino das coproduções com Espanha e com o Brasil e Presidente do Sindicato Nacional dos Profissionais do Cinema, utilizou esse mesmo jornal de atualidades segundo os seus interesses (que concordavam com a Política do Espírito de Ferro e portanto com a do SPN/SNI) 
como meio de autopromoção e justificação do seu posto de "produtor-realizador oficioso do regime" (Baptista, 2009).

Para isso, analisei 15 reportagens do Jornal Português e, a partir do seu enquadramento histórico e político, bem como dos seus meios de produção, tentei que se tornasse evidente que António Ferro, através das diretrizes da Política do Espírito e da sua cinefilia, e António Lopes Ribeiro, pela sua estratégia tentacular, que se fazia presente em todos os órgãos do meio do cinema, tiveram um interesse especial pelo cinema (em relação às outras artes), o que resultou em que "o cinema [fosse] exemplo [da] tentativa de o tornar num activo instrumento de doutrinação ao serviço do regime e da sua ideologia” (Cunha 2010, 11). Da política cinematográfica de Ferro resultou uma desproporcional proteção de certas figuras, em particular do próprio Lopes Ribeiro. Mais que isso, tentei tornar evidente o modo como Lopes Ribeiro instrumentalizou o Jornal Português, por exemplo, na parceria ibérica de coproduções iniciada primeiro entre revistas de cinema (Animatógrafo e Primer Plano), depois na troca de reportagens entre os jornais de atualidades (Jornal Português e NO$D O)$ e, mais tarde, na coprodução efetiva de longas metragens (facto que as próprias atualidades não deixaram de noticiar). Mas também, como referido, nas questões sindicais.

No entanto há outro aspeto, apenas abordado lateralmente, que importa considerar. Se a mão de António Lopes Ribeiro é evidente na manipulação dos conteúdos e dos "assuntos" de cinema, de que forma se fez notar o realizador o seu jornal de atualidades? Uma vez que os seus dois trabalhos na ficção de propaganda operaram a partir das formas e dos mecanismos das atualidades, e que grande parte da sua obra consiste em documentários institucionais, é importante olhar para o Jornal Português, mais do que um "instrumento valioso para compreender o que o regime foi e como se quis mostrar" (Costa 2015, 5), mas também como um espaço onde um artista operou ao longo de 14 anos e onde, certamente, terá experimentado soluções estéticas, formais e narrativas, algo que Luís Reis Torgal refere de passagem quando aborda o caso do Jornal Português, ao afirmar o "sentido ideológico, ao nível do argumento e da estética, assumidamente diferente do cinema de propaganda nazi, fascista ou soviético" (Torgal, 2009, 187). Falta ainda perceber em que medida existe essa diferença e qual é, afinal, a natureza narrativa e estética do "cinema de propaganda" no Jornal Português ${ }^{14}$. Estas e outras questões não fizeram parte da minha análise, mas merecem, certamente, atenção em estudos futuros.

\footnotetext{
${ }^{14}$ Não é, no entanto, despicienda a questão dos vários operadores de câmara que estiveram envolvidos e que pelo seu número (e pela reduzida verba disponibilizada) "fragilizaram a qualidade formal, técnica e estéticas das atualidades, havendo variações óbvias de qualidade entre edições especiais e regulares” (Piçarra 2015, 10).
} 


\section{BIBLIOGRAFIA}

ANTT - Arquivo Salazar. Plano de António Ferro para uma campanha de propaganda em toda a América e no Brasil em particular. PC12E, cx. 662, s/d: 1.

Baptista, Tiago e Rui Machado. 2015. "Sobre esta edição.” In Jornal Português: Revista Mensal de Atualidades 1938 - 1951, ed. de Tiago Baptista, 14-15. Lisboa: Cinemateca Portuguesa - Museu do Cinema, IP.

Baptista, Tiago. 2009. "Nacionalmente correcto: a invenção do cinema português", Revista Estudos do Século XX. 9. Acedido a 11 de maio de 2016. http://hdl.handle.net/10316.2/36549

Costa, João Bénard da. 2011. "Quando o que existia só existia se o cinema mostrava." In Salazar vai ao cinema II: a "Política do Espírito" no Jornal Português, entrevistado por Maria do Carmo Piçarra, 127-139. Lisboa: Drella Design.

Costa, José Manuel. 2015. "O Jornal como fonte de história - Cinco notas a propósito da edição do Jornal Português em DVD.” In Jornal Português: Revista Mensal de Atualidades 1938 - 1951, ed. Tiago Batista, 5-6. Lisboa: Cinemateca Portuguesa - Museu do Cinema, IP.

Cunha, Paulo. 2016. "Para uma história das histórias do cinema português." aniki - Revista Portuguesa da Imagem em Movimento. 3 (1): 36-45.

Cunha, Paulo. 2015. “Politicamente só existe o que o público sabe que existe'." Público, dezembro 17.

Cunha, Paulo. 2010. "As narrativas históricas no cinema português durante o Estado Novo (1932-74).” O Olho da História. 14. Acedido a 11 de maio de 2016. http://oolhodahistoria.org/n14/artigos/paulo.pdf

Félix, Ribeiro M. 1983. Filmes, Figuras e Factos da História do Cinema Português 1896-1949. Lisboa: Cinemateca Portuguesa - Museu do Cinema, IP.

Ferreira, Manuel Cintra. 2006. "Camões." Textos Cinemateca Portuguesa, Pasta 97, 59-60.

Ferro, António. 1931. "Imagem transcreve alguns trechos do livro de António Ferro 'Hollywood, capital das imagens'." Imagem, maio 22, 5-6.

Jornal Português: Revista Mensal de Atualidades - 1938-1951 [atualidades filmadas, DVD], Dir. António Lopes Ribeiro, SPAC, Portugal, 1938-1951, 1018 min., editado por Cinemateca Portuguesa - Museus do Cinema, IP, 2015. 
Loff, Manuel. 2015. "O Jornal Português (1938-40) na representação da nova ordem salazarista", Público, dezembro 10.

Matos-Cruz, José. 2012. "Feitiço do Império". Textos Cinemateca Portuguesa, Pasta 129, 269-272.

Mattos, Francisco Correia de. 1952. "Relatório sobre a edição do 'Jornal Português'”. In Jornal Português: Revista Mensal de Atualidades 1938 - 1951, ed. Tiago Baptista, 30-44. Lisboa: Cinemateca Portuguesa - Museu do Cinema, IP.

Nieves, José António. 1942. “Intercambio cinematográfico hispanolusitano". Primer Plano, julho 26, 3.

Palomar, Fernando Castan. 1946. "Un diretor entre dos películas". Primer Plano, dezembro 15, 4.

Pereira, Wagner Pinheiro. 2013. “1930-1939: O Cinema Português de Salazar”. In Cinema Português: Um Guia Essencial, ed. Paulo Cunha e Michelle Sales, 93-137. São Paulo: SESI-SP editora.

Piçarra, Maria do Carmo. 2015. “'A marcha do tempo' no Jornal Português: da projeção de Salazar e da 'portugalidade' à derrota da "política do Espírito"”. In Jornal Português: Revista Mensal de Atualidades 1938 - 1951, ed. Tiago Baptista, 7-11. Lisboa: Cinemateca Portuguesa - Museu do Cinema, IP.

Piçarra, Maria do Carmo. 2006. Salazar vai ao cinema: o Jornal Português de atualidades filmadas. Coimbra: Edições Minerva.

Piçarra, Maria do Carmo. 2011. Salazar vai ao cinema II: a "Política do Espírito" no Jornal Português. Lisboa: Drella Design.

Primer Plano. 1945. "Los realizadores de 'Inês de Castro' hablan de su colaboración”. Primer Plano, janeiro 14, 13-14.

Revolução de Maio, A [longa-metragem de ficção] Dir. António Lopes Ribeiro. SPN, Portugal, 1937, 110 min. 2"50. Acedido a 30 de dezembro de 2015. https://www.youtube.com/watch?v=bfwfEYBTxnU

Ribeiro, António Lopes. 1983. “Autobiografia”. In António Lopes Ribeiro, ed. José de Matos-Cruz. Lisboa: Cinemateca Portuguesa Museu do Cinema, IP.

Ribeiro, Carla. 2014. "António Ferro e a projeção atlântica de Portugal através do cinema”. Aniki: Revista Portuguesa da Imagem em Movimento. 1 (2).

Rodrigues, António. 2008. "Inês de Castro". Textos Cinemateca Portuguesa, Pasta 106, 15-16.

Rosas, Fernando. 1994. "O Estado Novo nos anos 30". In História de Portugal, ed. José Mattoso, vol. VII, 281-283. Lisboa: Círculo de Leitores. 
Rosas, Fernando, 2001. "O Salazarismo e o homem novo: ensaio sobre o Estado Novo e a questão do totalitarismo". Análise Social. 35 (157): 1031-1054.

Torgal, Luís Reis. 2009. "Cinema, Estética e Ideologia”. In Estados novos, estado novo: ensaios de história política e cultural vol. II, 175-214. Coimbra: Imprensa da Universidade de Coimbra.

Vieira, Patrícia. 2011. Cinema no Estado Novo. A Encenação do Regime. Lisboa: Edições Colibri.

Recebido em 2015-12-31. Aceite para publicação em 2016-06-16. 